\title{
Avaliação in vivo da anticlastogenicidade de extratos de plantas medicinais do gênero Miconia através do teste do micronúcleo
}

\section{In vivo evaluation of anticlastogenicity of extracts from medicinal plants of Miconia genus using the micronucleus test}

\author{
Juliana Mara Serpeloni ${ }^{1}$; Wagner Vilegas ${ }^{2}$; Eliana A. Varanda ${ }^{3}$; Ilce Mara S. Cólus ${ }^{4}$
}

\section{Resumo}

O gênero Miconia possui aproximadamente 1000 espécies, e para algumas, já foram descritas atividades biológicas como a analgésica e antimicrobiana. Esse trabalho teve como objetivo avaliar os possíveis efeitos protetores e citotóxicos dos extratos metanólicos de M. albicans, M. cabucu, M. rubiginosa e M. stenostachya e do extrato clorofórmico de M. albicans em células da medula óssea de camundongos na dose de $540 \mathrm{mg} / \mathrm{kg}$ p.c. Os extratos foram administrados via gavage e a ciclofosfamida (CPA) foi aplicada intraperitonealmente $1 \mathrm{~h}$, após a suplementação com os extratos. Todos os animais foram submetidos à eutanásia $30 \mathrm{~h}$ após o tratamento. As células analisadas foram retiradas da medula óssea de acordo com protocolo descrito por Schmid (1975). A citotoxicidade dos extratos foi avaliada pela percentagem de eritrócitos policromáticos (PCE) em 200 eritrócitos (PCE + NCE). Foram analisados 2000 PCEs por animal e anotadas as freqüências de MNPCEs. Os resultados obtidos mostraram que nenhum dos extratos associados à CPA apresentou efeito citotóxico e somente os extratos de $M$. rubiginosa, M. stenostachya mostraram efeito protetor ao DNA. A análise química dos extratos mostrou que as quatro espécies estudadas contêm, principalmente, flavonóides, compostos fenólicos e taninos. A caracterização fitoquímica desses extratos poderia contribuir para elucidação do efeito protetor apresentado somente pelas espécies M. rubiginosa e M. stenostachya, além de possibilitar o estudo de outras possíveis atividades terapêuticas.

Palavras-chave: Micronúcleo. Plantas medicinais. Anticlastogenicidade.

\begin{abstract}
The genus Miconia is comprised of approximately 1000 species. For some of them, biological activities have already been described such as the analgesic and the anti-microbial ones. The purpose of this work was to evaluate the possible protective and cytotoxic effects of the methanolic extract from M. albicans, M. cabucu, M. rubiginosa and M. stenostachya and the chloroformic extract from M. albicans in mice bone marrow cells in $540 \mathrm{mg} / \mathrm{kg}$ p.c. dose. The extracts were administered by means of forced feeding and the cyclophosphamide (CPA) was applied intraperitonially one hour after supplementation with extracts. All animals were submitted to euthanasia 30 hours after the treatment. The analyzed cells were extracted from mice bone marrow according to protocol described by Schmid (1975). The cytotoxicity of the extracts was evaluated through the percentage of polychromatic erythrocytes (PCE) in 200 erythrocytes (PCE + NCE). Two thousand PCEs of each animal were analyzed and the micronucleated polychromatic erythrocytes (MNPCEs) frequencies were scored. The results obtained indicated that

\footnotetext{
1 Aluna do Programa de Mestrado em Genética e Biologia Molecular da Universidade Estadual de Londrina. E-mail: julianaserpeloni@yahoo.com.br.

2 Instituto de Química de Araraquara, Universidade Estadual de São Paulo, Araraquara, SP, Brasil

3 Departamento de Ciências Biológicas, Faculdade de Ciências Farmacêuticas de Araraquara, Universidade Estadual de São Paulo, Araraquara, SP, Brasil.

4 Docente do Departamento de Biologia Geral da Universidade Estadual de Londrina.
} 
none of the extracts associated with the CPA showed cytotoxic effect and only the extracts of $M$. rubiginosa and M. stenostachya showed protective effect to DNA. Chemical analyses of the extracts showed that the four species studied contain mainly flavonoids, phenolic compounds and tannins. The phytochemical characterization of these extracts could contribute to elucidate the protective effect presented only by the species $M$. rubiginosa and $M$. stenostachya, besides making it possible the study of other therapeutic activities.

Keywords: Micronucleus. Medicinal plants. Anticlastogenicity.

\section{Introdução}

O uso de espécies vegetais para fins de tratamento e cura de doenças remonta ao início da civilização, desde o momento em que o homem começou um longo percurso de manuseio, adaptação e modificação destes recursos para seu próprio benefício. Atualmente, a natureza continua a ser uma grande fonte de medicamentos para a Humanidade. Nos últimos 20 anos, o interesse pelas plantas medicinais tem aumentado o volume de investigações científicas sobre seus efeitos biológicos em seres humanos e animais (VEIGA JÚNIOR; MACIEL, 2005).

Para a Organização Mundial da Saúde, plantas medicinais são todas aquelas, silvestres ou cultivadas, que podem ser utilizadas como recurso para prevenir, aliviar, curar ou modificar um processo fisiológico normal ou patológico, ou como fonte de fármacos e de seus precursores (ARIAS, 1999), enquanto fitoterápicos são produtos medicinais acabados e etiquetados, cujos ingredientes ativos são formados por partes aéreas ou subterrâneas de plantas, ou outro material vegetal, ou combinações destes, em estado bruto ou em formas de preparações vegetais. Por material vegetal, entendem-se sucos, resinas, óleos fixos, óleos voláteis e qualquer outro de natureza semelhante (ORGANIZACIÓN MUNDIAL DE LA SALUD - OMS, 1991).

São vários os exemplos de medicamentos que foram desenvolvidos de fontes naturais, especialmente de plantas, incluindo, entre outros, a morfina, os curares, os digitálicos e muitos medicamentos usados no tratamento do câncer (vimblastina, vincristina e taxol), as estatinas usadas nas dislipidemias, os imunossupressores e vários antibióticos. Atualmente, há um grande interesse das indústrias farmacêuticas pelo uso da biodiversidade como fonte de novos fármacos (CALIXTO, 2001).

O papel das plantas medicinais na quimioprevenção do câncer vem sendo muito investigado e apresenta resultados promissores. Quimioprevenção pode ser definida como inibição ou reversão da carcinogênese, um processo que começa com células de morfologia normal e termina com a formação de tumores invasivos (KELLOFF et al., 1994). Nas últimas duas décadas, um aumento nas evidências obtidas a partir de estudos epidemiológicos e de laboratório, tem demonstrado que algumas plantas, como um todo ou por meio de compostos isolados, têm efeitos protetores substanciais na carcinogênese humana (SURH; FERGUSON, 2003).

Embora muitos remédios de origem vegetal tenham sido relatados como anticarcinogênicos, somente poucos têm ganhado substancial popularidade como terapias alternativas para a doença. Terapias complementares ou adjuvantes, como os próprios nomes sugerem, são tipicamente usadas para suplementar a medicina ou prover a atenuação dos efeitos adversos por meio de tratamentos não invasivos, com pouco ou nenhum efeito adverso (CASSILETH, 1996).

O presente estudo teve como objetivo avaliar a atividade anticlastogênica de extratos vegetais de quatro espécies de plantas medicinais do cerrado brasileiro, pertencentes ao gênero Miconia: M. albicans, M. cabucu, M. rubiginosa, M. stenostachya. Todos os extratos foram anteriormente avaliados in vivo por nosso grupo nas concentrações de 200, 400 e $540 \mathrm{mg} / \mathrm{Kg}$ p.c. e nenhum deles apresentou mutagenicidade em nenhuma das 
concentrações testadas (trabalho submetido). A partir desses resultados, a maior concentração de cada extrato foi escolhida para ser avaliada quanto à sua capacidade de reduzir danos no DNA causados pelo quimioterápico ciclofosfamida, por meio do teste do micronúcleo em células da medula óssea de camundongos.

\section{Materiais e métodos}

\section{Animais}

Foram utilizados camundongos Swiss albinos (Mus musculus), com aproximadamente $30 \mathrm{~g}$ de peso corpóreo ao início dos tratamentos, provenientes do Biotério Central da Universidade Estadual de Londrina(Paraná-Brasil), mantidosindividualmente em caixas de polietileno com tampa grade, de acordo com as recomendações do Canadian Council on Animal Care (OLFERT; CROSS; McWILLIAM, 1993). Esse projeto de pesquisa foi aprovado pelo Comitê de Ética da Universidade Estadual Paulista (Unesp- Araraquara), de acordo com o protocolo número 50-2004.

\section{Extratos vegetais}

As partes aéreas de Miconia cabucu Hoehne foram coletadas em abril de 2005 em PariqueraAçu, estado de São Paulo, Brasil, e identificadas por Prof. Dr. Jorge Yoshio Tamashiro do Instituto de Biologia, Unicamp, São Paulo. A exsicata (no. 1430) foi depositada no herbário da Universidade Estadual de Campinas, Brasil.

Miconia rubiginosa (Bonpl.) (exsicata BOTU 25.376) e Miconia stenostachya D.C (exsicata BOTU 25.377) foram coletadas em março de 2005 em Palmeiras da Serra, Pratânia, Estado de São Paulo, Brasil e foram identificadas pelo Dr. Luiz Fernando Rolim de Almeida, do Instituto de Botânica, UNESP. As exsicatas foram depositadas no herbário "Irina Delanova Gemtchujnicov" BOTU do Instituto de Biociências, UNESP, Botucatu.

Miconia albicans (Sw.) Steud foi coletada na Universidade Estadual de São Paulo (UNESP), campus de Bauru e identificada pela Dra. Anne L. Dokkedal. A exsicata foi depositada no herbário do Departamento de Biologia da UNESP/Bauru (UNBA), com o número ALD 145.

Os materiais vegetais foram secos em estufa a $40^{\circ} \mathrm{C}$ e moídos em moinho de facas. Os extratos foram preparados por maceração com $\mathrm{CHCl}_{3}$ para extrair os componentes mais apolares e com $\mathrm{MeOH}$ para a extração dos constituintes polares. Posteriormente foram concentrados em evaporador rotativo à pressão reduzida. As massas obtidas estão relatadas na Tabela 1. A extração de cada solvente foi realizada três vezes, a fim de se obter um bom rendimento.

Tabela 1. Quantidade de massa obtida após maceração das folhas das espécies estudadas

\begin{tabular}{lccc}
\hline Espécies & Planta seca $\mathbf{( g )}$ & \multicolumn{2}{c}{ Extratos (\% de rendimento) } \\
\hline & & $\mathbf{C H C l}_{3}$ & $\mathbf{M e O H}$ \\
M. albicans & 500 & 3.1 & 15.0 \\
M. cabucu & 600 & ne & 3.3 \\
M. rubigibnosa & 500 & ne & 9.3 \\
M. stenostachya & 500 & ne & 14.6 \\
\hline
\end{tabular}

ne: não estudado. 
O clean up por SPE-C $\mathrm{C}_{18}$ foi realizado de acordo com o procedimento descrito na Figura 1. Essa metodologia foi desenvolvida a fim de se obter frações enriquecidas de metabólitos da mesma classe. As frações obtidas foram analisadas separadamente por HPLC-UV-DAD e a análise dos espectros de UV obtidos sugere a presença de derivados de ácidos fenólicos de alta polaridade, taninos, flavonóides glicosilados e catequinas (RODRIGUES et al, 2007).

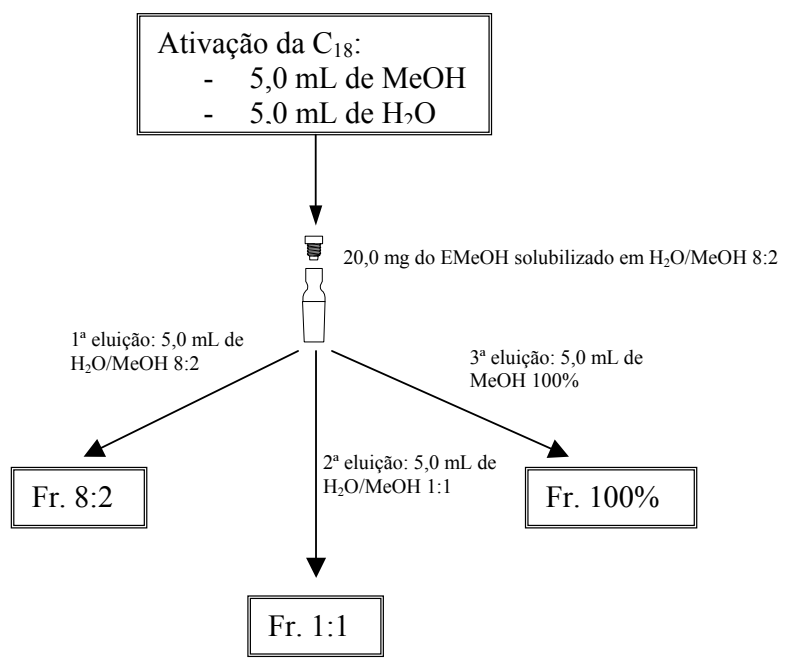

Figura 1. Etapas de preparação dos extratos para análise por HPLC-UV-DAD (Rodrigues et al., 2007).

\section{Ciclofosfamida (CPA)}

A CPA $\left(\mathrm{C}_{2} \mathrm{H}_{15} \mathrm{CL}_{2} \mathrm{~N}_{2} \mathrm{P} . \mathrm{H}_{2} \mathrm{O}\right)$ é um agente antineoplásico e imunossupressor altamente mutagênico, utilizado em tratamentos quimioterápicos. Caracteriza-se por ser um pó cristalino, fino, branco, com pouco ou nenhum odor, e possui peso molecular de 279,1 (ANDERSON et al., 1995).

CPA (Sigma- 6055-19-2) foi utilizada como controle-positivo na dose de $40 \mathrm{mg} / \mathrm{kg}$ p.c., sendo diluída em água destilada e administrada via intraperitoneal.

\section{Tratamento dos animais}

Os animais foram distribuídos em grupos de 10 (5 machos e 5 fêmeas) para cada tratamento e receberam $0,1 \mathrm{~mL}$ de cada uma das soluções empregadas para cada $10 \mathrm{~g}$ de peso corpóreo, além de água e alimento ad libitum no decorrer de todo o período de tratamento.

Os extratos foram avaliados na concentração de $540 \mathrm{mg} / \mathrm{Kg}$ p.c, escolhida com base nos estudos prévios de mutagenicidade. Para isso, foi realizado um tratamento simultâneo do extrato com o agente indutor de danos, a ciclofosfamida (na dose de 40 $\mathrm{mg} / \mathrm{Kg} \mathrm{p.c).} \mathrm{Esta} \mathrm{foi} \mathrm{administrada} \mathrm{em} \mathrm{dose} \mathrm{única,}$ via intraperitoneal, uma hora depois do extrato vegetal, água destilada (controle negativo) ou solvente serem administrados via gavage. Com essa diferença de uma hora entre os tratamentos esperase ter ocorrido a entrada simultânea da CPA e dos componentes do extrato, da água e do solvente na corrente sanguínea dos animais, uma vez que os compostos (com exceção da CPA) estarão sujeitos ao trânsito digestivo. Para avaliação dos efeitos protetores dos extratos de Miconia contra os danos clastogênicos promovidos pela CPA os animais foram divididos nos seguintes grupos:

Água destilada via gavage.

Tween $8 \%$ via gavage.

CPA via intraperitonea.l

$\mathrm{CPA}+$ Tween $8 \%$ via gavage

$\mathrm{CPA}+\mathrm{EMeOH}$ de M. albicans.

$\mathrm{CPA}+\mathrm{ECHCl}_{3}$ de M. albicans.

$\mathrm{CPA}+\mathrm{EMeOH}$ de M. cabucu.

$\mathrm{CPA}+\mathrm{EMeOH}$ de M. rubiginosa .

$\mathrm{CPA}+\mathrm{EMeOH}$ de $M$. stenostachya.

Todos os animais tratados sofreram eutanásia 30 horas após os tratamentos, por deslocamento cervical. 


\section{Análise do material obtido da medula óssea}

Teste do Micronúcleo em células da Medula Óssea de camundongos

A técnica utilizada para o estudo de micronúcleos em células de medula óssea foi a descrita por Schmid (1975). Após a morte dos animais, os fêmures foram retirados e as epífises distais cortadas. Com uma seringa contendo $1 \mathrm{ml}$ de soro bovino fetal (Gibco), a medula óssea foi retirada e depositada num tubo de centrífuga contendo também $1 \mathrm{~mL}$ desse soro. O material foi, então, homogeneizado com pipeta Pasteur e, em seguida, os tubos contendo as células da medula óssea foram centrifugados a $800 \mathrm{rpm}$ por 10 minutos e o sobrenadante descartado. O pellet foi ressuspendido no restante do sobrenadante (cerca de 0,3 mL). Em lâminas de vidro limpas e secas, com o auxílio de uma lamínula de vidro, foram realizados esfregaços com uma gota de solução das células obtidas. As lâminas foram fixadas 24 horas após a realização dos esfregaços com metanol absoluto por 10 minutos. A coloração foi realizada 24 horas após a fixação das células, com Giemsa 5\% diluído em tampão fosfato. As lâminas secaram ao ar e, então, foram armazenadas em geladeira até a análise citológica.

Foram analisados 2000 eritrócitos policromáticos (PCEs) por animal para verificação da freqüência de células micronucleadas nos diferentes tratamentos efetuados. A análise foi realizada em microscópio binocular de luz comum (Nikon), com objetiva de 100x (imersão) em teste cego, de acordo com os critérios utilizados para análise de micronúcleos previamente descritos por Titenko-Holland et al. (1997) e Huber, Streng e Bauchinger (1983).

Teste de Citotoxicidade

A determinação da citotoxicidade dos compostos-testes na medula óssea foi feita por meio da porcentagem de eritrócitos policromáticos (PCE) em relação ao total de eritrócitos (PCE + $\mathrm{NCE}$ ), onde NCE são eritrócitos normocromáticos (RIBEIRO, 2003). As lâminas foram as mesmas utilizadas na análise do micronúcleo em células da medula óssea.

\section{Porcentagem de redução de danos}

A porcentagem de redução de danos (diminuição da freqüência média de células micronucleadas) dos extratos que mostraram atividade anticlastogênica foi calculada de acordo com Manoharan e Banerjee (1985) e Waters et al. (1990), usando a fórmula:

$(\%)$ Redução $=\underline{\text { freqüência de MNPCEs em A }- \text { freqüência de MNPCEs em B }} \times 100$ freqüência de MNPCEs em A - freqüência de MNPCEs em C

onde "A" é o grupo de células tratadas com CPA (controle positivo); "B" é o grupo de células tratadas com os extratos associados à $\mathrm{CPA} \mathrm{e}$ "C" $\mathrm{C}$ grupo controle negativo.

\section{Análise Estatística}

Para a análise estatística dos resultados foi empregado o teste de análise de variância (ANOVA), seguido pelo teste de Tukey, no qual foram comparadas entre si as médias de MNPCEs e as relações PCE/NCE obtidas para cada grupo de tratamento.

\section{Resultados}

A Tabela 2 mostra as freqüências de MNPCEs observadas na medula óssea dos animais tratados com os extratos associados à CPA e também as relações PCE/NCE obtidas em cada grupo de tratamento, ambos resultados obtidos também para os grupos controle negativo (água destilada), controle positivo (CPA) e controle do solvente (Tween $8 \%$ ). 
Tabela 2. Número médio de MNPCEs em um total de 2000 células analisadas por animal por tratamento para a avaliação dos efeitos protetores de diferentes extratos de plantas do gênero Miconia.

\begin{tabular}{|c|c|c|c|c|c|}
\hline $\begin{array}{l}\text { TRATAMENTOS } \\
\text { (mg/kg p.c.) }\end{array}$ & $\mathbf{N}^{0}$ Animais & MNPCES & $\begin{array}{c}\mathrm{X} \pm \mathrm{DP} / \\
\text { animal }\end{array}$ & $\% \mathrm{R}$ & $\begin{array}{c}\text { RAZÃO PCE/ } \\
\text { PCE+NCE } \\
\text { X } \pm \text { DP }\end{array}$ \\
\hline Água Destilada & 10 & 34 & $3,4 \pm 1,27^{\mathrm{a}}$ & & $0,586 \pm 0,04$ \\
\hline Tween $8 \%$ & 10 & 27 & $2,7 \pm 1,64^{\mathrm{a}}$ & & $0,662 \pm 0,06$ \\
\hline CPA (40) & 10 & 353 & $35,3 \pm 5,91^{b}$ & & $0,656 \pm 0,10$ \\
\hline Tween 8\% + CPA (40) & 10 & 338 & $33,8 \pm 2,86^{b}$ & & $0,641 \pm 0,07$ \\
\hline \multicolumn{6}{|l|}{ Extratos (540)+ CPA (40) } \\
\hline M. albicans МеОН & 10 & 348 & $34,8 \pm 4,32^{b}$ & & $0,642 \pm 0,07$ \\
\hline M. albicans $\mathrm{CHCl}_{3}$ & 10 & 304 & $30,4 \pm 4,62^{b}$ & & $0,603 \pm 0,06$ \\
\hline М. сависи МеОН & 10 & 344 & $34,4 \pm 4,72^{b}$ & & $0,598 \pm 0,06$ \\
\hline M. rubiginosa $\mathrm{MeOH}$ & 10 & 186 & $18,6 \pm 1,96^{\mathrm{c}}$ & 52,30 & $0,610 \pm 0,05$ \\
\hline M. stenostachya $\mathrm{MeOH}$ & 10 & 254 & $25,4 \pm 3,53^{\mathrm{c}}$ & 31,03 & $0,540 \pm 0,03$ \\
\hline
\end{tabular}

X \pm DP: Média \pm Desvio padrão; PCE: eritrócito policromático; NCE: eritrócito normocromático; MNPCE: eritrócito policromático micronucleado; $\mathrm{MeOH}$ : extrato metanólico; $\mathrm{CHCl}_{3:}$ Extrato clorofórmico; Cyclophosphamide (CPA): positive control; \%R: Porcentagem de redução de danos

* Valores seguidos pela mesma letra não diferem estatisticamente entre si

Pode-se observar que a freqüência de células micronucleadas diminuiu apenas para os grupos tratados com extratos das espécies Miconia rubiginosa e Miconia stenostachya, sendo as porcentagens de redução de danos calculadas de, respectivamente, 52,35 e $31,03 \%$ (Tabela 2 ).

Não foi observada nenhuma diferença estatisticamente significativa entre as relações PCE/NCE obtidas em cada grupo de tratamento, mostrando que a associação dos extratos com a CPA não induziu citotoxicidade (Tabela 2).

\section{Discussão}

Recentemente, apesar de várias drogas clássicas derivadas de plantas terem perdido muito espaço para os fármacos de origem sintética, outras têm aparecido e recebido atenção especial e prestígio terapêutico, evidenciando que fármacos derivados de plantas e fitoterápicos têm o mesmo valor fármacoeconômico. Um indício do renascimento de fármacos derivados de fontes vegetais é a grande quantidade e progresso da pesquisa clínica, especialmente no campo dos agentes anticancerígenos, onde podem ser citados taxol, podofilotoxina e camptotecina, bem como dos compostos antimaláricos, como por exemplo a artemisinina (DE SMET, 1997).

Ainda que exista uma ampla variedade de compostos ativos de origem natural que possam ser futuramente relacionados como medicamentos, os desafios estão centrados principalmente em métodos farmacológicos apropriados e ensaios biológicos que possam predizer uma certa eficácia clínica à substância em estudo (HOSTETTMAN; MARSTON; HOSTETTMAN, 1997). 
A elucidação dos componentes ativos presentes nas plantas, bem como seus mecanismos de ação, vem sendo um dos maiores desafios para a química farmacêutica, bioquímica e a farmacologia. As plantas contêm inúmeros constituintes e seus extratos, quando testados, podem apresentar efeitos sinérgicos entre os diferentes princípios ativos devido à presença de compostos de classes ou estruturas diferentes contribuindo para a mesma atividade. No estudo da atividade biológica de extratos vegetais é importante a seleção de bioensaios para a detecção do efeito específico. Os sistemas de ensaio devem ser simples, sensíveis e reproduzíveis (GEBHARDT, 2000).

O teste do micronúcleo, capaz de detectar quebras ou perdas cromossômicas, encontra-se em grande realce há muito tempo, por ser utilizado em pesquisas de mutagênese e tratar-se de um método que apresenta, entre outras vantagens, o fato de ser relativamente rápido e barato (SLESISKI; GUZZIE, 1988; ZALACAIN et al., 2005). O primeiro protocolo para o teste do micronúcleo em camundongos foi desenvolvido por Schmid (1975), usando células da medula óssea de roedores. Nesse procedimento os micronúcleos são contados em eritrócitos jovens, pois permanecem no citoplasma após a expulsão dos núcleos e são facilmente reconhecíveis devido às suas formas arredondadas e coloração característica.

No presente estudo, a ciclofosfamida, droga empregada no tratamento de uma série de neoplasias, artrites reumatóides e também usada como imunossupressora em casos de transplantes de órgãos, foi utilizada como controle-positivo. Em células somáticas, a ciclofosfamida produz micronúcleos em ratos, camundongos e hamsters chineses, principalmente porquebras cromossômicas (ANDERSON et al., 1995). A CPA associada aos extratos de quatro plantas medicinais pertencentes ao gênero Miconia em camundongos e a observação das células da medula óssea após tratamento agudo indicaram que somente os extratos de Miconia rubiginosa e Miconia stenostachya diminuíram a freqüência de células micronucleadas em relação ao controle positivo (CPA).

Efeitos protetores mais consistentes foram observados por nosso grupo em células do sangue periférico de camundongos, com o uso do o teste do micronúcleo, e isso se deve ao fato de todos os quatro extratos avaliados foram capazes de reduzir as freqüências de células micronucleadas produzidas pela CPA (trabalho submetido). De acordo com o relato do "The Collaborative Study Group for the Micronucleus Test" (1992), é difícil comparar precisamente as freqüências dos eritrócitos jovens da medula óssea e do sangue periférico, porque as populações podem ser diferentes de acordo com o critério para a classificação de PCEs e RETs (reticulócitos). PCE jovem e NCE maduro são fáceis de classificar, mas as células em transição de um estado para o outro são um desafio para o observador (PARTON; HOFFMAN; GARRIOTT, 1996). Em RETs, é menos provável que ocorram problemas na análise porque a coloração por laranja de acridina permite uma classificação menos subjetiva e mais precisa.

A análise química dos extratos avaliados revelou, principalmente, a presença de flavonóides, taninos e outros compostos fenólicos e os dados disponíveis na literatura acerca das atividades biológicas destes compostos auxiliam a compreensão dos resultados obtidos. Segundo Ribeiro e Seravalli (2004), os flavonóides compõem uma ampla classe de substâncias de origem natural, e englobam uma classe importante de pigmentos naturais encontrados com freqüência na natureza, unicamente em vegetais. Entretanto, esses compostos possuem uma série de propriedades farmacológicas que os fazem atuar sobre os sistemas biológicos (LOPES et al., 2003), por exemplo, como antioxidantes. A dieta mediterrânea, rica em frutas frescas e vegetais, tem sido associada com a baixa incidência de doenças cardiovasculares e câncer, principalmente devido à elevada proporção de compostos bioativos como vitaminas, flavonóides e polifenóis (BENAVENTE-GARCÍA et al., 1999). Em recente revisão, Neuhouser (2004), analisando 
mais de uma dezena de publicações, encontrou diminuição no risco de câncer de $40 \%$ a $58 \%$ entre as pessoas que mais ingeriam os alimentos que contêm flavonóides em comparação com as que menos ingeriam, após períodos que variaram de 13 a 30 anos de seguimento.

Os taninos podem ser encontrados abundantemente em raízes, galhos, folhas, flores, frutos e sementes das árvores. Ele constitui-se de carboidrato simples, goma hidroxicoloidais, fenóis e aminoácidos (MARTINEZ, 1996; DUTRA, 1997). Os taninos são descritos na literatura como compostos com atividades antimutagênica (DAUER et al., 2003), antioxidante (HASLAM, 1996), antitumoral (SALEEM et al., 2002), dentre outras.

Os compostos químicos isolados a partir dos extratos das quatro espécies avaliadas foram caracterizados quimicamente, porém, apenas de forma qualitativa. Diferenças quantitativas significativas entre os compostos poderiam justificar os efeitos protetores apresentados somente pelos extratos de Miconia rubiginosa e Miconia stenostachya. Sendo assim, sugere-se a realização de estudos para quantificação dos compostos isolados que possibilitem identificar quais os responsáveis pelos efeitos protetores observados. Esses extratos poderão ser promissores na busca por compostos adjuvantes aos tratamentos quimioterápicos, uma vez que poderiam atuar nas células sadias diminuindo os efeitos adversos do tratamento do câncer.

\section{Agradecimentos}

Os autores agradecem à Fundação de Amparo à Pesquisa do Estado de São Paulo (FAPESP) pelo suporte financeiro do Programa BIOTAFapesp e à Coordenação de Aperfeiçoamento de Pessoal de Nível Superior (CAPES/DS) pela bolsa cedida à J.M Serpeloni e ao Conselho Nacional de Desenvolvimento Científico e Tecnológico (CNPq), pelas bolsas produtividade concedidas aos Drs. W. Vilegas, E. A.Varanda e I. M. S. Cólus.

\section{Referências}

ANDERSON, D.; BISHOP, J. B.; GARNER, R. C.; OSTROSKY-WEGMAN, P.; SELBY, P. B. Cyclophosphamide: review of its mutagenicity for an assessment of potencial germ cell risks. Mutation Research, Amsterdam, v. 330, n. 2, p. 115-181, 1995.

ARIAS, T. D. Glosario de medicamentos: desarollo, evaluación y uso. Washington: Organización Panamericana de La Salud/Organización Mundial de La Salud, 1999.

BENAVENTE-GARCIA,O.; CASTILLO, J.;LORENTE, J.; ORTUNO, A.; DEL RIO, J. A. Antioxidant activity of phenolics extracted from Olea europaea L. leaves. Food Chemistry, London, v. 68, n. 4, p. 457-462, 1999.

CALIXTO, J. B. Plantas medicinais sob a ótica da química moderna. 1.ed. Chapecó: Argos Editora Universitária, 2001.

CASSILETH, B. R. Alternative and complementary cancer treatments. The oncologist, Dayton, v. 1, n. 3, p. 173-179, 1996

DAUER, A.; HENSEL, A.; LHOSTE, E.; KNASMULLER, S.; MERSCH-SUNDERMANN, V. Genotoxic and antigenotoxic effects of catechin and tannins from the bark of Hamamelis virginiana $\mathrm{L}$. in metabolically competent, human hepatoma cells (HEP G2) using single cell gel electrophoresis. Phytochemistry, New York, v. 63, n. 2, p. 199-207, 2003.

DE SMET, P. A. G. M. The role of plant-derived drugs and herbal medicines in healthcare. Drugs, Auckland, v. 54, n. 6, p. 801-840, 1997.

DUTRA, C. Avaliação do potencial de actinomicetos no trabalho de efluentes de indústrias que processam madeira. 1997. Tese. (Mestrado em Saúde Pública) Universidade Federal do Rio de Janeiro, Rio de Janeiro.

GEBHARDT, R. In vitro screening of plant extracts and phytopharmaceuticals: novel approaches for the elucidation of active compounds and their mechanisms. Planta Medica, Stuttgart, v. 66, n.2, p. 99-105, 2000

HASLAM, E. Natural polyphenols (vegetal tannins) as drug: Possible modes of action. Journal of Natural Products, Cincinnati, v. 59, n. 2, p. 205-215, 1996.

HOSTETTMAN, K.; MARSTON, A.; HOSTETTMAN, M. Preparative chromatography techniques. New York: Verlag Berlim Heidelberg, 1997.

HUBER, R; STRENG, S.; BAUCHINGER, M. The suitability of the human lymphocyte micronucleus assay system for biological dosimetry. Mutation Research, Amsterdam, v. 111, n. 2, p. 185-193, 1983. 
KELlOFF, G. J.; BOONE, C. W.; STEELE, V. E.; CROWELL, J. A.; LUBET, R.; SIGMAN; C. C. Progress in cancer chemoprevention: perspectives on agent selection and short-term clinical intervention trials. Cancer research, Baltimore, v. 54, supl., p. 2015-2024, 1994.

LOPES, R. M.; OLIVEIRA, T. T.; NAGEM, T. J.; SILVA, P. A. Flavonóides. Biotecnologia: Ciência \& Desenvolvimento, Brasília, v. 17, n. 1, p. 18-22, 2003.

MANOHARAN, K.; BANERJEE, M R. $\beta$-Carotene reduces sister chromatid exchange induce chemical carcinogens in mouse mammary cells in organ culture. Cell Biology International Reports, London, v. 9, n. 8, p. 783-789, 1985.

MARTINEZ, F. L. Taninos Vegetais e suas aplicações. Universidade de Havana/Cuba. Universidade do Estado do Rio de Janeiro, 1996.

NEUHOUSER, H. L. Dietary flavonoids and cancer risk; evidence from human population studies. Nutrition and Cancer, Philadelphia, v. 50, n. 1, p. 1-7, 2004.

OLFERT, E. D.; CROSS, B. M.; McWILliAM, A. A. The guide to the care and use of experimental animals. Canadá: Canadian Council on Animal Care, 1993. v. 1.

ORGANIZACIÓN MUNDIAL DE LA SALUD - OMS. Pautas para la evaluación de Medicamentos Herbarios. Genebra: OMS, 1991.

PARTON, J. W.; HOFFMAN, W. P.; GARRIOTT, M.L. Validation of an automated image analysis micronucleus scoring system. Mutation Research, Amsterdam, v. 370, n. 1, p. 65-73, 1996.

RIBEIRO, E. P.; SERAVALLI, E. A. G. Química de alimentos. São Paulo: Editora Edgard Blucher: Instituto Mauá de Tecnologia, 2004.

RIBEIRO, L. R. Teste do micronúcleo em medula óssea in vivo In: RIBEIRO, L. R.; SALVADORI, D. M. F.; MARQUES, E. K. Mutagênese Ambiental. Canoas: Ed. Ulbra, 2003. p. 173-200.

RODRIGUES. J.; RINALDO, D.; SANTOS, L. C.; VILEGAS, W. An unusual $\mathrm{C}_{6}-\mathrm{C}_{6}$, linked flavonoid of Miconia cabucu (Melastomataceae). Phytochemistry, New York, v. 68, n. 13, p. 1781-1784, 2007.
SALEEM, A.; HUSHEEM, M.; HARKONEN, P.; PIHLAJA, K Inhibition of cancer cell growth by crude extract and the phenolics of Terminalia chebula Retz. fruit. Journal of Ethnopharmacology, Lausanne, v. 81, n. 3, p. 327-336, 2002.

SCHMID, W. The micronucleus test. Mutation Research, Amsterdam, v. 31, n. 1, p. 9-15, 1975.

SLESISKI, R. S; GUZZIE, P. J. Review of Recent Advances in the Development and Application of the Micronucleus Test System. In: BALLANTYNE, B. (Ed.) Perspectives in basic and applied toxicology. Bristol: Wright, 1988. p. 161-176.

SURH, Y.; FERGUSON, L. R. Dietary and medicinal antimutagens and anticarcinogens: molecular mechanisms and chemopreventive potential - highlights of a symposium. Mutation research, Amsterdam, v. 524, n. 1, p. 1-8, 2003.

THE COLLABORATIVE STUDY GROUP FOR THE MICRONUCLEUS TEST. Micronucleus test with mouse peripheral blood erythrocytes by acridine orange supravital staining: The summary report of the $5^{\text {th }}$ collaborative study by CSGMT/ JEMS - MMS. Mutation Research, Amsterdam, v. 278, n. 1, p. 83-98, 1992.

TITENKO-HOLLAND, N.; WINDHAM, P.; KOLACHANA, F.; REINISCH, S.; PARVATHAM, A. M.; OSORIO, M. T. Genotoxicity of malathion in human lymphocytes assessed using the micronucleus assay in vitro and in vivo: a study of malathion-exposed workers. Mutation Research, Amsterdam, v. 388, n. 1, p. 85-95, 1997.

VEIGA JÚNIOR., V. F.; MACIEL, M. A. M. Plantas medicinais: cura segura? Química Nova, São Paulo, v. 28, n.3, p. 519-528, 2005.

WATERS, M. D.; BRADY, A. L.; STACK, H. F.; BROXKMAN, H. E. Antimutagenic profiles for some model compounds. Mutation Research, Amsterdam, v. 238, n. 1, p. 57-85, 1990.

ZALACAIN, M.; SIERRASESÚMAGA, L.; PATIÑO, A. El ensayo de micronúcleos como medida de inestabilidad genética inducida por agentes genotóxicos. Anales del Sistema Sanitario de Navarra, Pamplona, v. 28, n. 2, p. 227-236, 2005. 
